\title{
Annealing effects on strain and stress sensitivity of polymer optical fibre based sensors
}

Pospori, A.; Marques, C. A. F.; Zubel, M. G.; Saez-Rodriguez, D.; Nielsen, Kristian; Bang, Ole; Webb, D. J.

Published in:

Proceedings of the Spie

Link to article, DOI:

$10.1117 / 12.2227473$

Publication date:

2016

Document Version

Publisher's PDF, also known as Version of record

Link back to DTU Orbit

Citation (APA):

Pospori, A., Marques, C. A. F., Zubel, M. G., Saez-Rodriguez, D., Nielsen, K., Bang, O., \& Webb, D. J. (2016). Annealing effects on strain and stress sensitivity of polymer optical fibre based sensors. In Proceedings of the Spie (Vol. 9886). [98860V] SPIE - International Society for Optical Engineering. Proceedings of SPIE - The International Society for Optical Engineering https://doi.org/10.1117/12.2227473

\section{General rights}

Copyright and moral rights for the publications made accessible in the public portal are retained by the authors and/or other copyright owners and it is a condition of accessing publications that users recognise and abide by the legal requirements associated with these rights.

- Users may download and print one copy of any publication from the public portal for the purpose of private study or research.

- You may not further distribute the material or use it for any profit-making activity or commercial gain

- You may freely distribute the URL identifying the publication in the public portal 


\title{
Annealing effects on strain and stress sensitivity of polymer optical fibre based sensors
}

\author{
A. Pospori*a , C. A. F. Marques ${ }^{\mathrm{a}}$, M. G. Zubel ${ }^{\mathrm{a}}$, D. Sáez-Rodríguez ${ }^{\mathrm{b}}$, K. Nielsen ${ }^{\mathrm{c}}$, O. Bang ${ }^{\mathrm{c}}$, D. J. \\ $\mathrm{Webb}^{\mathrm{a}}$ \\ ${ }^{a}$ Aston Institute of Photonic Technologies, Aston University, Aston Triangle, Birmingham, B7 4ET, \\ United Kingdom \\ ${ }^{\mathrm{b}}$ Optical and Quantum Communications Group, ITEAM Research Institute, Universitat Politecnica \\ de Valencia, 46022 Valencia, Spain \\ ${ }^{c}$ DTU Fotonik, Department of Photonics Engineering, DK-2800 Kgs. Lyngby, Denmark \\ *a.posporis@aston.ac.uk; orcid.org/0000-0003-4866-1361
}

\begin{abstract}
The annealing effects on strain and stress sensitivity of polymer optical fibre Bragg grating sensors after their photoinscription are investigated. PMMA optical fibre based Bragg grating sensors are first photo-inscribed and then they were placed into hot water for annealing. Strain, stress and force sensitivity measurements are taken before and after annealing. Parameters such as annealing time and annealing temperature are investigated. The change of the fibre diameter due to water absorption and the annealing process is also considered. The results show that annealing the polymer optical fibre tends to increase the strain, stress and force sensitivity of the photo-inscribed sensor.
\end{abstract}

Keywords: POF, Bragg gratings, annealing, strain sensitivity, stress sensitivity, polymer fibre sensors

\section{INTRODUCTION}

Polymer optical fibre Bragg grating (POFBG) sensors have received attention recently because of their potentially enhanced performance in certain applications compared to their silica counterparts ${ }^{1}$. Polymer optical fibres (POF) offer greater elasticity ${ }^{2}$ and higher failure strain ${ }^{3}$. The lower Young's modulus of polymer materials ${ }^{2,4}$ renders POFBG sensors more sensitive to strain ${ }^{5}$, stress $^{6}$, pressure ${ }^{7}$ and acoustic wave detection ${ }^{8}$. The large negative thermo-optic coefficient of polymer compared with the small positive thermo-optic coefficient of glass ${ }^{9-11}$ can also offer to POFBG sensors enhanced sensitivity to temperature variations ${ }^{12,13}$. Their biocompatibility ${ }^{14}$ can provide additional applications in the biomedical sector and the water absorption in some polymers such as PMMA can be used for humidity monitoring ${ }^{15,16}$.

Some of the drawbacks of POFs are their high losses and their viscoelastic nature. The viscoelasticity can introduce hysteresis and creep effects when cyclic loading is applied to the fibre, which can influence the accuracy of the sensor reading. It has been demonstrated that these effects can be reduced by thermally anneal the fibres ${ }^{17}$. POFBG annealing was first used for multiplexing purposes ${ }^{7,18}$, but then it was shown that annealing can also change the performances of the POF based sensors. Enhanced strain $^{19}$ and humidity ${ }^{20}$ sensitivity of POFBG sensors and longer temperature operational range ${ }^{21}$ has been reported. In this study, we investigate the annealing effects on strain and stress sensitivity of POFBG sensors. We report also a simple but well-controlled annealing process.

\section{EXPERIMENTAL DETAILS}

\subsection{POFBG fabrication}

Figure 1 illustrates the POFBG fabrication and interrogation setup. By using the phase mask technique, POFBGs with Bragg wavelength in the $850 \mathrm{~nm}$ region are photo-inscribed using a continuous-wave He-Cd laser (Kimmon IK3301RG) with an output power of $30 \mathrm{~mW}$ and wavelength of $325 \mathrm{~nm}$. Single-mode micro-structured PMMA optical fibre doped with benzyl dimethyl ketal ${ }^{22}$ is used. A super-luminescent diode (Superlum SLD-371) and an optical spectrum analyser (HP 86142A) were connected to the input arms of an $850 \mathrm{~nm}$ single-mode silica fibre coupler and the POF was connected to one of the output arms of the coupler using the butt-coupling method (Figure 1). This arrangement allowed for Bragg wavelength spectra monitoring in reflection. Various grating lengths are obtained $(1.2 \mathrm{~mm}-10 \mathrm{~mm})$, but we 
believe the grating length does not play any role in our experimental results because we monitor the wavelength shift and not the grating strength. After the photo-inscription, each POF was placed and glued into a FC/PC connector to facilitate monitoring of the Bragg wavelength.

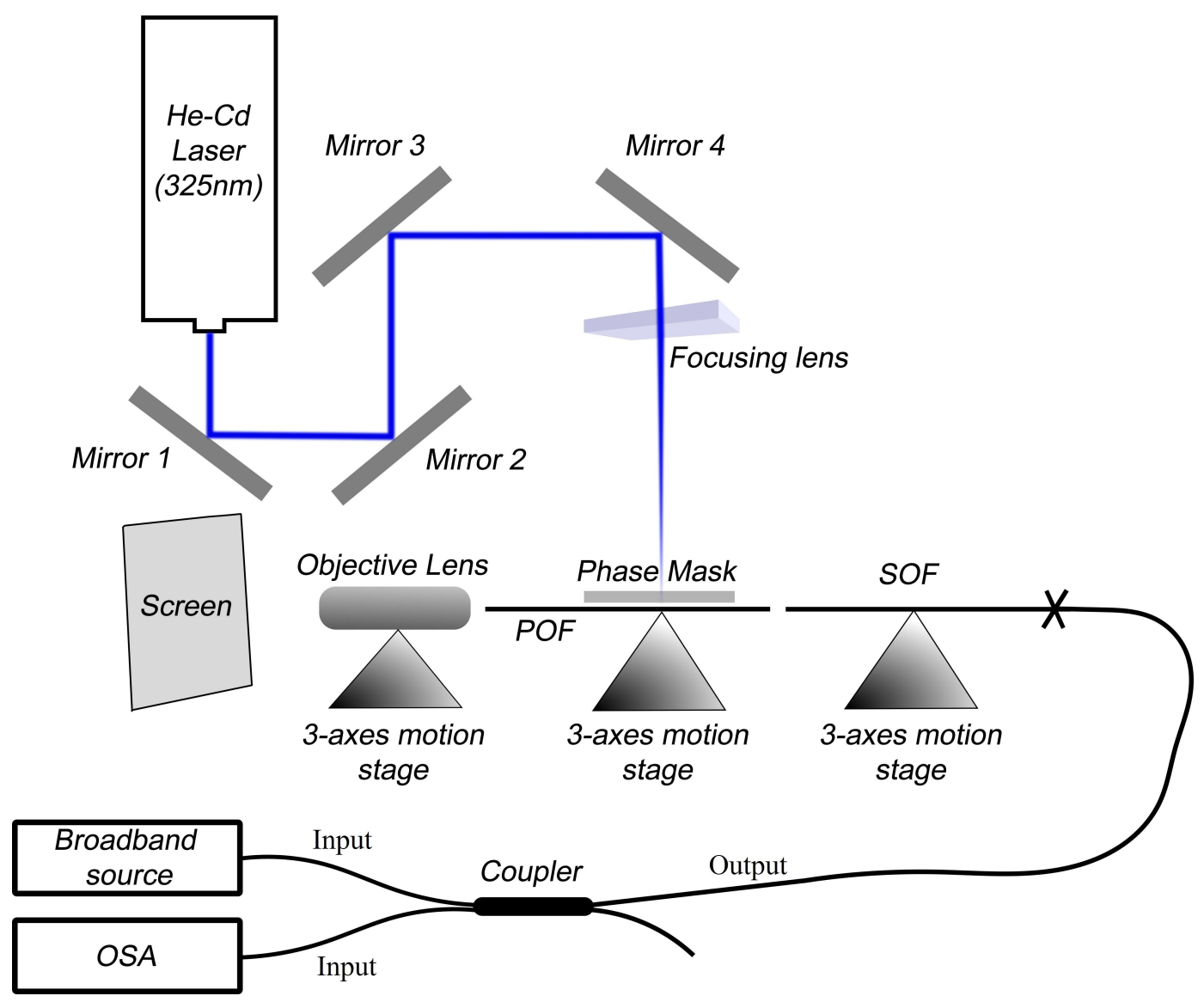

Figure 1: POFBG fabrication and interrogation setup

\subsection{Characterisation of strain and stress sensitivity}

The performance of the fabricated sensors is characterised before and after the annealing process. In order to measure their strain sensitivities, each sensor was attached between a movable stage and a fixed support by using magnetic fibre clamps. By moving one stage along the fibre axis, each POF was strained by $0.5 \%$. The Bragg wavelength shift $(\Delta \lambda)$ due to strain $(\varepsilon=0.005)$ was monitored using the same interrogation method described above and the strain sensitivity for each device is calculated by $\Delta \lambda / \varepsilon$. For the stress sensitivities measurements, each fibre was held perpendicular to the ground and a mass of a known value was added at the opposite end of the POF to stress the fibre. Stress $(\sigma)$ can be calculated by

$$
\sigma=\frac{F}{A}=\frac{m g}{\pi\left(\frac{d}{2}\right)^{2}},
$$

where $F$ is the gravity force and $A$ is the area where the force is applied. The gravity force can be found by considering the added mass $m$ and the Earth's gravity acceleration value $g$ which equals $9.8 \mathrm{~m} / \mathrm{s}^{2}$. The area $A$ can be found if the fibre 
diameter $d$ at the POFBG location is measured using an optical microscope. The stress sensitivity can be determined by $\Delta \lambda / \sigma$. Force sensitivity which is independent of the fibre diameter can be also calculated by $\Delta \lambda / F$.

\subsection{Annealing process}

Thermal annealing was only demonstrated previously by placing POFs in an oven or climatic chamber for extended periods of time (typically from several hours to several days) ${ }^{17-19,23,24}$. In our case, POFs are annealed with a low cost and yet well-known procedure and for much shorter time (2 to 30 minutes). Fibres were placed in a cylindrical metallic tank with diameter of $127 \mathrm{~mm}$ and height of $22 \mathrm{~mm}$ filled with hot water. The water was heated using a hot plate under the metallic tank. The temperature of water was monitored by using a mercury thermometer (FISONS THL-290-050J). Two annealing temperatures $55 \pm 2{ }^{\circ} \mathrm{C}$ and $60 \pm 2{ }^{\circ} \mathrm{C}$ were investigated. The reason why hot water is used is because the equilibrium relative humidity value during annealing is a known parameter $(100 \%)$ and controlling that parameter during annealing is important in order to have the same annealing conditions for all sensors. In addition, annealing in a high humidity environment has been shown to offer enhanced humidity sensitivity compared to lower humidity annealing ${ }^{20}$ and this might be beneficial in our case. To ensure more accurate results, the POF's diameter was measured before and after annealing using an optical microscope in order to calculate the applied stress each time.

\section{RESULTS AND DISCUSSION}

Figure 2 depicts the wavelength shift of sensor 5 during the annealing process. The initial Bragg wavelength before the fibre is placed into hot water was $862.70 \mathrm{~nm}$. After of 30 minutes annealing, just before the fibre is removed from the hot water, the Bragg wavelength was $821.88 \mathrm{~nm}$. When the fibre was removed from hot water, the Bragg wavelength positive shifted by $1.19 \mathrm{~nm}$ due to the temperature change $\left(60 \pm 2{ }^{\circ} \mathrm{C}\right.$ to room temperature). Therefore, the Bragg wavelength shifted from $862.70 \mathrm{~nm}$ to $823.07 \mathrm{~nm}$ indicating a total wavelength shift of $39.63 \mathrm{~nm}$ due to thermal annealing.

Table 1 lists the strain sensitivities of 9 POFBG sensors before and after the annealing process. Table 2 and Table 3 show the annealing effects on stress and force sensitivities respectively for the same sensors. Results show that in all cases the annealing enhanced the strain, stress and force sensitivities of the POFBG sensors. Different annealing times and temperatures were tried. However, higher annealing temperatures or longer annealing times do not clearly show an additional sensitivity enhancement and no conclusions can be drawn in this matter.

The initial sensitivity values are different for each sensor and our explanation is that each fibre has slightly different mechanical properties due to rapid fluctuations in fibre drawing conditions (drawing speed and temperature). The polymer molecule chains align with the fibre axis during the drawing process and when these stretched elastomers cool down, they create an internal stress in the fibre ${ }^{25,26}$. This internal stress results in less mobile molecular chains than in the bulk material, which affects the Young's modulus. Therefore, the fluctuations during the drawing condition can alter the elasticity along the fibre axis, potentially causing the significant variation in the initially measured sensitivities. These fluctuations can also be linked to fibre diameter variations ( $10 \%$ over lengths of a few centimeters in our case). Despite however the differences in the mechanical properties of each fibre, the sensitivities of the POFBG sensors were improved in all cases after the thermal annealing process. The reason for the improvement is likely because we exposed the material to temperatures above the $\beta$ relaxation of $\mathrm{PMMA}^{27}$, where the conformation of the polymer backbone chain can be reorganised and the stressed molecular chains can $\operatorname{relax}^{28,29}$. The molecular relaxation can increase the elasticity of the material and enhance the sensitivity of the POFBG sensors.

In order also to investigate the influence of the initial fibre water content on the annealing results, the following method was used. Before the annealing process, sensors 2, 8 and 9 were placed in a tank filled with water at room temperature for 44, 20 and 43 hours respectively and their sensitivities were compared with the other sensors. The high water content in the POFs before annealing did not provide any clear effects on the overall strain and stress sensitivity enhancement after annealing. Sensors 2, 8 and 9 were tested again one day after the initial assessment when they had achieved equilibrium with ambient conditions and no significant change in their measured sensitivities was observed. 


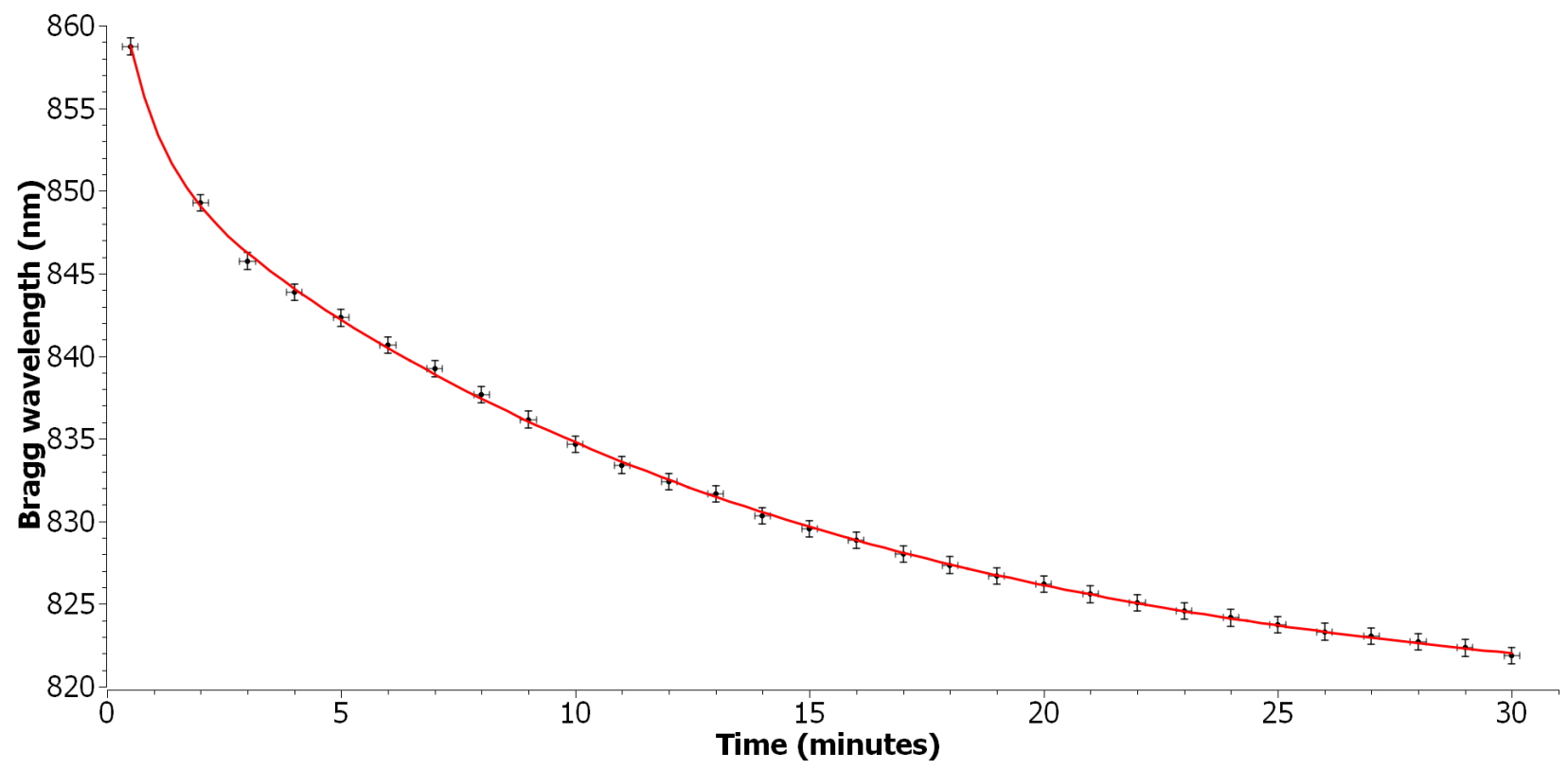

Figure 2: Wavelength shift of sensor 5 during the annealing process

Table 1: Strain sensitivities of POFBG sensors before and after thermal annealing

\begin{tabular}{|c|c|c|c|c|c|}
\hline Sensor & $\begin{array}{c}\text { Annealing time } \\
\text { (minutes) }\end{array}$ & $\begin{array}{c}\text { Annealing } \\
\text { temperature } \\
\mathbf{\pm 2}\left({ }^{\circ} \mathrm{C}\right)\end{array}$ & $\begin{array}{c}\text { Strain sensitivity } \\
\text { before annealing } \\
(\mathbf{p m} / \mu \varepsilon)\end{array}$ & $\begin{array}{c}\text { Strain sensitivity } \\
\text { after annealing } \\
(\mathbf{p m} / \mu \varepsilon)\end{array}$ & $\begin{array}{c}\text { Sensitivity } \\
\text { improvement } \\
\text { after annealing }\end{array}$ \\
\hline 1 & 2 & 60 & 0.664 & 0.726 & $+9.3 \%$ \\
\hline 2 & 4 & 60 & 0.716 & 0.688 & $+23 \%$ \\
\hline 3 & 4 & 60 & 0.536 & 0.850 & $+28 \%$ \\
\hline 4 & 30 & 60 & 0.728 & 0.944 & $+22 \%$ \\
\hline 5 & 30 & 50 & 0.772 & 0.880 & $+23 \%$ \\
\hline 6 & 30 & 55 & 0.714 & 0.876 & $+21 \%$ \\
\hline 7 & 30 & 55 & 0.726 & 0.906 & $+24 \%$ \\
\hline 8 & 30 & 55 & 0.692 & 0.884 & $+23 \%$ \\
\hline
\end{tabular}


Table 2: Stress sensitivities of POFBG sensors before and after thermal annealing

\begin{tabular}{|c|c|c|c|c|c|}
\hline Sensor & $\begin{array}{l}\text { Annealing time } \\
\text { (minutes) }\end{array}$ & $\begin{array}{l}\text { Annealing } \\
\text { temperature } \\
\pm 2\left({ }^{\circ} \mathrm{C}\right)\end{array}$ & $\begin{array}{l}\text { Stress sensitivity } \\
\text { before annealing } \\
\quad(\mathrm{pm} / \mathrm{kPa})\end{array}$ & $\begin{array}{l}\text { Stress sensitivity } \\
\text { after annealing } \\
(\mathbf{p m} / \mathbf{k P a})\end{array}$ & $\begin{array}{l}\text { Sensitivity } \\
\text { improvement } \\
\text { after annealing }\end{array}$ \\
\hline 1 & 2 & 60 & 0.137 & 0.217 & $+58 \%$ \\
\hline 2 & 4 & 60 & 0.180 & 0.260 & $+44 \%$ \\
\hline 3 & 4 & 60 & 0.147 & 0.201 & $+33 \%$ \\
\hline 4 & 30 & 60 & 0.196 & 0.258 & $+32 \%$ \\
\hline 5 & 30 & 60 & 0.173 & 0.202 & $+17 \%$ \\
\hline 6 & 30 & 55 & 0.184 & 0.220 & $+20 \%$ \\
\hline 7 & 30 & 55 & 0.178 & 0.205 & $+15 \%$ \\
\hline 8 & 30 & 55 & 0.182 & 0.221 & $+21 \%$ \\
\hline 9 & 30 & 55 & 0.194 & 0.231 & $+19 \%$ \\
\hline
\end{tabular}

Table 3: Force sensitivities of POFBG sensors before and after thermal annealing

\begin{tabular}{|c|c|c|c|c|c|}
\hline Sensor & $\begin{array}{c}\text { Annealing time } \\
(\mathbf{m i n u t e s})\end{array}$ & $\begin{array}{c}\text { Annealing } \\
\text { temperature } \\
\mathbf{\pm} \mathbf{2}\left({ }^{\circ} \mathbf{C}\right)\end{array}$ & $\begin{array}{c}\text { Force sensitivity } \\
\mathbf{b e f o r e} \text { annealing } \\
(\mathbf{p m} / \boldsymbol{\mu N})\end{array}$ & $\begin{array}{c}\text { Force sensitivity } \\
\text { after annealing } \\
(\mathbf{p m} / \boldsymbol{\mu} \mathbf{N})\end{array}$ & $\begin{array}{c}\text { Sensitivity } \\
\text { improvement } \\
\text { after annealing }\end{array}$ \\
\hline 1 & 2 & 60 & 0.0109 & 0.0137 & $+26 \%$ \\
\hline 2 & 4 & 60 & 0.0109 & 0.0143 & $+31 \%$ \\
\hline 3 & 4 & 60 & 0.0109 & 0.0137 & $+26 \%$ \\
\hline 4 & 30 & 60 & 0.0137 & 0.0179 & $+31 \%$ \\
\hline 5 & 30 & 60 & 0.0134 & 0.0146 & $+21 \%$ \\
\hline 6 & 30 & 55 & 0.0136 & 0.0165 & $+15 \%$ \\
\hline 7 & 30 & 55 & 0.0116 & 0.0133 & $+19 \%$ \\
\hline 8 & 30 & 55 & 0.0119 & 0.0142 & $+19 \%$ \\
\hline 9 & 30 & 55 & 0.0122 & 0.0145 & $+9 \%$ \\
\hline
\end{tabular}

\section{CONCLUSION}

Thermal annealing of POF was originally used by scientists for multiplexing purposes. Later, an annealing-induced sensitivity improvement in the POFBG sensors was noticed when they were used in strain, temperature and humidity monitoring applications. In the current work, POF annealing was shown to increase not only the strain, but also the stress and force sensitivities of the POFBG sensors. A low-cost, well-controlled annealing method is also presented where just hot water is enough for the annealing. 


\section{ACKNOWLEDGMENT}

The research leading to these results has received funding from the People Programme (Marie Curie Actions) of the European Union's Seventh Framework Programme FP7/2007-2013/ under REA grant agreement No. 608382. This work was supported by Marie Curie Intra European Fellowships included in the 7th Framework Program of the European Union (projects PIEF-GA-2013-628604 and PIEF-GA-2011-302919).

\section{REFERENCES}

[1] D. J. Webb, "Fibre Bragg grating sensors in polymer optical fibres", Measurement Science and Technology, 26(9), 092004 (2015).

[2] J. G. A. Griffiths, "Tables of physical and chemical constants. By G. W. C. Kaye and T. H. Laby", The Analyst, 73(873), 704 (1948).

[3] M. C. J. Large, J. Moran, and L. Ye, "The role of viscoelastic properties in strain testing using microstructured polymer optical fibres (mPOF)", Measurement Science \& Technology, 20, (2009).

[4] M. K. Szczurowski, L. Khan, D. J. Webb et al., "Measurements of stress-optic coefficient and Young's modulus in PMMA fibers drawn under different conditions", Proc. SPIE 7714 (2010).

[5] S. Kiesel, P. Van Vickle, K. Peters et al., "Intrinsic polymer optical fiber sensors for high-strain applications", Proc. SPIE 6167, 616713-616713-11 (2006).

[6] T. X. Wang, Y. H. Luo, G. D. Peng et al., "High-sensitivity stress sensor based on Bragg grating in BDK-doped photosensitive polymer optical fiber", 8351 (2012).

[7] C. Marques, A. Pospori, D. Sáez-Rodríguez et al., "Fiber optic liquid level monitoring system using microstructured polymer fiber Bragg grating array sensors: performance analysis", International Society for Optics and Photonics 9634, 96345V-4 (2015).

[8] A. Stefani, S. Andresen, W. Yuan et al., "Dynamic Characterization of Polymer Optical Fibers", Ieee Sensors Journal, 12, 3047-3053 (2012).

[9] R. M. Waxler, and G. Cleek, "Effect OF temperature and pressure on refractive-index of some oxide glasses", Journal of Research of the National Bureau of Standards, Section A: Physics and Chemistry(6), 755-763 (1973).

[10] L. Eldada, and L. W. Shacklette, "Advances in polymer integrated optics", Selected Topics in Quantum Electronics, IEEE Journal of, 6(1), 54-68 (2000).

[11] Z. Zhang, P. Zhao, P. Lin et al., "Thermo-optic coefficients of polymers for optical waveguide applications", Polymer, 47, 4893-4896 (2006).

[12] H. B. Liu, H. Y. Liu, G. D. Peng et al., "Strain and temperature sensor using a combination of polymer and silica fibre Bragg gratings", Optics Communications, 219, 139-142 (2003).

[13] X. S. Cheng, W. W. Qiu, W. X. Wu et al., "High-sensitivity temperature sensor based on Bragg grating in BDK-doped photosensitive polymer optical fiber", Chinese Optics Letters, 9, (2011).

[14] F. Bischoff, "Organic polymer biocompatibility and toxicology", Clinical chemistry, 18(9), 869-894 (1972).

[15] T. Watanabe, N. Ooba, Y. Hida et al., "Influence of humidity on refractive index of polymers for optical waveguide and its temperature dependence", Applied Physics Letters, 72, 1533-1535 (1998).

[16] W. Zhang, D. J. Webb, and G. D. Peng, "Investigation Into Time Response of Polymer Fiber Bragg Grating Based Humidity Sensors", Journal of Lightwave Technology, 30, 1090-1096 (2012).

[17] A. Abang, and D. J. Webb, "Effects of annealing, pre-tension and mounting on the hysteresis of polymer strain sensors", Measurement Science and Technology, 25(1), (2014).

[18] I. P. Johnson, D. J. Webb, and K. Kalli, "Utilisation of thermal annealing to record multiplexed FBG sensors in multimode microstructured polymer optical fibre", Proc. SPIE 7753, 7327-7753 (2011).

[19] W. Yuan, A. Stefani, M. Bache et al., "Improved thermal and strain performance of annealed polymer optical fiber Bragg gratings", Optics Communications, 284, 176-182 (2011).

[20] G. Woyessa, K. Nielsen, A. Stefani et al., "Temperature insensitive hysteresis free highly sensitive polymer optical fiber Bragg grating humidity sensor", Optics Express, 24(2), 1206-1213 (2016).

[21] K. Carroll, A. Argyros, K. Kalli et al., "Extending the working temperature range of Bragg gratings in microstructured polymer optical fibre by annealing", International Cooperative of Plastic Optical Fibers (2007).

[22] D. Saez-Rodriguez, K. Nielsen, H. K. Rasmussen et al., "Highly photosensitive polymethyl methacrylate microstructured polymer optical fiber with doped core", Optics Letters, 38, 3769-3772 (2013). 
[23] K. E. Carroll, C. Zhang, D. J. Webb et al., "Thermal response of Bragg gratings in PMMA microstructured optical fibers.", Optics express, 15, 8844-50 (2007).

[24] W. Zhang, and D. J. Webb, "Factors influencing the temperature sensitivity of PMMA based optical fiber Bragg gratings", Proc. SPIE 9128 (2014).

[25] S. Fakirov, [Oriented polymer materials] Wiley Online Library, (1996).

[26] S. Kukureka, G. Craggs, and I. Ward, "Analysis and modelling of the die drawing of polymers", Journal of materials science, 27(12), 3379-3388 (1992).

[27] G. Wypych, [Handbook of solvents] ChemTec Publishing, (2001).

[28] E. Muzeau, J. Perez, and G. P. Johari, "Mechanical spectrometry of the .beta.-relaxation in poly(methyl methacrylate)", Macromolecules, 24(16), 4713-4723 (1991).

[29] K. Schmidt-Rohr, A. S. Kulik, H. W. Beckham et al., "Molecular Nature of the .beta. Relaxation in Poly(methyl methacrylate) Investigated by Multidimensional NMR", Macromolecules, 27(17), 4733-4745 (1994). 